\title{
A Unified Theory of Structural Change*
}

\author{
María Dolores Guilló \\ University of Alicante \\ guillo@merlin.fae.ua.es
}

\author{
Chris Papageorgiou ${ }^{\dagger}$ \\ International Monetary Fund \\ cpapageorgiou@imf.org
}

\author{
Fidel Perez-Sebastian \\ University of Alicante \\ fidel@merlin.fae.ua.es
}

April 2011

\begin{abstract}
This paper uses dynamic general equilibrium and computational methods, inspired by the multisector growth model structure in Stephen Turnovsky's work, to develop a theory that unifies two of the traditional explanations of structural change: sector-biased technical change and non-homothetic preferences. The theory is based on an overlapping-generations growth model with endogenous technical-change and non-homothetic preferences. An expanding-variety setup with two different R\&D technologies, agricultural, and non-agricultural, is employed. The analysis, based on numerical simulations, shows that the biased technical-change hypothesis finds most support in the data. It also points to production-side specific factors, such as asymmetries in cross-sector knowledge spillovers, as explanatory factors of the bias in technical change.
\end{abstract}

JEL Classification: O13, O14, O41.

Key words: multi-sector growth model, structural change, agriculture and nonagriculture $R \& D$, directed innovation, hon-homothetic preferences.

\footnotetext{
${ }^{*}$ The paper was prepared for a keynote speach in the Workshop in Honor of Stephen J. Turnovsky May 2010. We thank two referees and the editor, Walter Fisher, for their excellent comments and suggestions. We also benefited from discussions with Joshua Aizenman, Santanu Chatterjee, Gerhard Sorger, Stephen Turnovsky, and participants at the Society of Computational Economics session at the 2010 ASSA meeting in Atlanta. Financial support from Ministerio de Ciencia e Innovación and FEDER funds under project SEJ-2007-62656, and from Instituto Valenciano de Investigaciones Económicas is gratefully acknowledged. The views expressed in this study are the sole responsibility of the authors and should not be attributed to the International Monetary Fund, its Executive Board, or its management.

${ }^{\dagger}$ Corresponding author: International Monetary Fund, 700 19th Street, N.W. Washington, DC 20431, email: cpapageorgiou@imf.org, tel: (202) 623-7503, fax: (202) 589-7503.
} 


\section{Introduction}

Stephen Turnovsky's graduate textbook Methods of Macroeconomic Dynamics made a powerful mark on the field of macroeconomics by providing crucial building blocks and useful applications of general equilibrium intertemporal macroeconomic models. A notable offspring of these methods is a class of models employing multisectoral dynamics in a long-run growth context, also developed by Turnovsky (and coauthors; including, among many others, Fisher and Turnovsky, 1998; Eicher and Turnovsky 1999a,b, 2001; Alvarez-Cuadrado, Monteiro and Turnovsky, 2004; and Turnovsky, 2004), which has been the cornerstone of an entire research agenda which to this date is vibrant and keeps branching out to new applications of macroeconomics.

This paper uses dynamic general equilibrium and computational methods that we first discovered as junior assistant professors studying Turnovsky's book and extends our earlier work (Papageorgiou and Perez-Sebastian, 2004; 2006; 2007) inspired by the multi-sector growth model structure in Turnovsky's previous and more recent work. More specifically, the goal of this paper is to construct a model that unifies two of the traditional explanations of structural transformation; namely, sector-biased technical change and non-homothetic preferences. Acemoglu (2009, Chapter 20) defends the importance of integrating both approaches and points to this as an avenue for future research.

A well-documented feature of modern growth commonly called structural change or structural transformation is the decline of agriculture and the rise of services. ${ }^{1}$ Structural transformation has been studied extensively, resulting in two prominent albeit divergent theories. ${ }^{2}$ The former is based on consumer non-homothetic preferences pioneered by Konsamut, Rebelo and Xie (2001). The later builds on sectorbiased technical change and stems from the influential contributions of Baumol (1967) and more recently Ngai and Pissarides (2007).

\footnotetext{
${ }^{1}$ This reallocation process has been documented by earlier contributions including Clark (1940), Kuznets (1957), and Chenery (1960).

${ }^{2}$ See e.g., Kuznets (1966) and Baumol (1967), Echevarria (1997), Parente et al. (2000), Caselli and Coleman (2001), and Strulik and Weisdorf (2008).
} 
Konsamut, Rebelo and Xie (2001) were the first to present a model consistent with both the Kaldor facts of constant growth rate, capital-output ratio, real rate of return to capital, and input shares in national income, and the dynamics of sectoral labor reallocation. These authors construct a model in which balanced growth is consistent with structural change assuming a preference specification in which the income elasticity of demand is less than one for agricultural goods, equal to one for manufacturing goods, and greater than one for services. Their additional assumption of non-homothetic preferences was sufficient, in an otherwise standard neoclassical model, to allow for structural change.

An alternative theory based on the technological hypothesis, was proposed by Baumol (1967) and formalized by Ngai and Pissarides (2007) who develop a formal framework that builds on the response of hours of work to the uneven distribution of technological change across production sectors. Ngai and Pissarides show that if there are two sectors, one characterized by a larger total factor productivity (TFP) growth, hours of work rise in the stagnant sector if the two goods have a relatively large degree of complementarity; otherwise labor moves in the direction of the progressive sector. ${ }^{3}$

In this paper, we examine whether a more general approach with endogenous innovation can encompass both of these influential theories of structural transformation, and whether their conclusions hold in it. In particular, we first ask whether the sector-biased technical change hypothesis can follow from the non-homothetic preferences hypothesis. We examine the idea that freeing labor from agriculture to feed other economic sectors might require a larger total factor productivity (TFP) growth in agriculture; and that, as a consequence, biased TFP growth could be an endogenous response to the non-homotheticity of the utility function. Second, the paper searches for features of technological change that can explain the observed evolution of sectoral TFP.

In order to accomplish these goals, we construct a multisector overlapping-generations model of endogenous technical-change and economic growth. The production side

\footnotetext{
${ }^{3}$ Recent work by Buera and Kaboski (2009) provide further support in favor of biased technical change while Iscan (2010) presents quantitative results that suggest that non-homothetic preferences had a larger weight in structural transformation in the early stages of the process. In Iscan's model, technical change is exogenous.
} 
of the economy follows Romer (1990) and Jones (1995). The setup incorporates expanding-varieties of intermediate goods that are designed using sector-specific R\&D technologies. Production is disaggregated into two activities: agriculture, and nonagriculture, while preferences are non-homothetic. We formalize the notion that inventors choose the kind of technological improvements that they create, which also connects this paper to the literature on directed technical change (see e.g., Acemoglu 2002, 2003). Unlike these papers however, we focus on ideas directed to different sectors instead of different inputs.

A setup in which $R \& D$ technologies are symmetric across sectors is first considered. Results from numerical simulations imply that the sector-biased technical change hypothesis cannot follow from non-homothetic preferences alone, because the latter hypothesis generates both larger TFP growth and labor inflows in the same sector, irrespective of the elasticity of substitution between final goods. To generate reasonable dynamics, the long-run value of TFP in agriculture needs to be larger than in other sectors. This is prevented in our baseline model by the lower weight of agricultural-goods consumption in the utility function. We then show that by modifying the R\&D technologies to consider benefits to agriculture from cross-sector knowledge spillovers, the extended model predictions are now able to reproduce the main patterns of TFP growth observed in the data.

The rest of the paper is organized as follows. Section 2 introduces the baseline model while section 3 examines its predictions. Section 4 presents results in the modified model where the R\&D technologies allow for cross-sector knowledge spillovers. Section 5 concludes.

\section{The Model}

\subsection{Households}

We consider an economy composed of overlapping generations of individuals. The size of generation $t$ is $L_{t}$, and grows exogenously at rate $n$. Individuals have preferences over consumption of agricultural and non-agricultural goods. They are endowed with one unit of labor when young that is inelastically supplied to the production activities. 
For simplicity, we assume that consumption occurs only in the second period of life, thus abstracting from consumption/saving decisions. ${ }^{4}$ At time $t$, a representative consumer is solving the following problem:

$$
\max \left\{v\left(c_{a t+1}, c_{n t+1}\right)=\left[\sum_{i=a, n} \gamma_{i}\left(c_{i t+1}-\bar{c}_{i}\right)^{(\varepsilon-1) / \varepsilon}\right]^{\varepsilon /(\varepsilon-1)}\right\},
$$

subject to

$$
P_{a t+1} c_{a t+1}+c_{n t+1}=\left(1+r_{t+1}\right) w_{t}
$$

where $\varepsilon \in(0, \infty) ; c_{a t}$ and $c_{n t}$ are consumption at date $t$ of the agricultural and non-agricultural products, respectively $;^{5} r$ and $w$ are the rental rates of capital and labor; $P_{a t}$ is the price of agricultural goods; $\gamma_{a}+\gamma_{n}=1 ; \bar{c}_{i}$ represents a minimum subsistence-consumption level if positive, or a minimum endowment level if negative. All prices in the model are expressed in units of the non-agricultural goods. The right-hand side of the budget constraint reflects equality between interest rate and the return to capital.

The first-order conditions to this problem provide the optimal weights in the consumption bundle as follows:

$$
\left(\frac{P_{a t}}{\gamma_{a}}\right)^{\varepsilon}\left(c_{a t}-\bar{c}_{a}\right)=\left(\frac{1}{\gamma_{n}}\right)^{\varepsilon}\left(c_{n t}-\bar{c}_{n}\right) .
$$

A larger weight in the utility function or a lower price contribute to increase demand for that good.

\subsection{Final-good production}

A large number of firms produce goods using labor and capital, while each firm produces output $Y_{i t}$ only in one sector $i$, with $i \in\{a, n\}$. At date $t$, capital employed is

\footnotetext{
${ }^{4}$ This does not have any impact on our results because saving only affects the total amount of capital, whereas our findings are driven by differences in the allocation of resources between the two sectors. Capital is not an important determinant of these differences given our assumption that the elasticity of capital is the same in the agriculture and non-agriculture production functions.

${ }^{5}$ Having three sectors such as agriculture, manufacturing, and services, instead of two, would complicate the model without adding a significant change to the basic message of the paper.
} 
composed of a mass $A_{i t}$ of differentiated producer durables. The production technology is given by:

$$
Y_{i t}=L_{i t}^{1-\alpha} \int_{0}^{A_{i t}}\left[x_{i t}(z)\right]^{\alpha} d z
$$

where $x_{i t}(z)$ and $L_{i t}$ are the amounts of equipment type $z$ and labor employed by sector $i$ in period $t$.

Firms choose the amount of each type of capital good that they want to buy, and the amount of labor that they want to hire so as to maximize profits. They solve the following problem:

$$
\max _{\left\{x_{i t}(z), L_{i t}\right\}}\left\{P_{i t} L_{i t}^{1-\alpha} \int_{0}^{A_{i t}}\left[x_{i t}(z)\right]^{\alpha} d z-\int_{0}^{A_{i t}} p_{i t}(z) x_{i t}(z) d z-w_{t} L_{i t}\right\} ;
$$

where $p_{i t}(z)$ is the price of durable good type $z$ specific to sector $i$.

Solving this problem obtains the inverse demand functions:

$$
\begin{aligned}
x_{i t}(z) & =\left(\frac{\alpha P_{i t}}{p_{i t}(z)}\right)^{1 /(1-\alpha)} L_{i t}, \\
L_{i t} & =(1-\alpha) \frac{P_{i t} Y_{i t}}{w_{t}} .
\end{aligned}
$$

\subsection{Intermediate-goods production}

Production technology (4) employs different types of capital goods. The manufacturing process of these goods requires investing raw capital coming from saved manufacturing output. We adopt the simplest technology to manufacture capital products: one unit of capital can be converted at no cost into one unit of any variety of intermediate goods. Firms that successfully produce these varieties hold exclusive property rights on the designs, which allows them to practice monopoly pricing. We assume that these property rights expire in one generation. ${ }^{6}$ Capital also depreciates fully after one generation.

The problem of a firm that produces variety $j$ for sector $i$ is:

$$
\max _{x_{i t}(j)}\left[p_{i t}(j)-\left(1+r_{t}\right)\right] x_{i t}(j)
$$

\footnotetext{
${ }^{6}$ Assuming that a generation is equal to 30 years, implies a depreciation rate of ideas of about $10 \%$, figure consistent with the evidence provided by Caballero and Jaffe (1993).
} 
where $p_{i t}(j)$ is given by the inverse demand function of intermediate good $x_{i t}(j)$, that is, by equation (6). The monopolist charges a markup $\eta$ equal to the inverse of the elasticity of substitution between intermediate goods in final output production. More specifically, the optimal decision, standard in the literature, is given by:

$$
p_{i t}(j)=\eta_{i}\left(1+r_{t}\right)=p_{i t}, \text { with } \eta_{i}=\frac{1}{\alpha}=\eta, \quad \forall j .
$$

Since the price is the same for all varieties of intermediate goods, and they enter symmetrically in final-good production, the amount demanded for each of them will also be the same, $x_{i}(j)=x_{i} \forall j$. Profits then equal:

$$
\pi_{i t}(j)=(\eta-1)\left(1+r_{t}\right) x_{i t}=\pi_{i t}, \text { also } \forall j
$$

\section{$2.4 \quad R \& D$ sector}

Under the assumption of free entry into the $R \& D$ activity, there is a continuum of firms that invest in deliberate $R \& D$ effort directed to create sector-specific varieties of intermediate goods. These firms rent labor supplied by young individuals at the beginning of period $t$. Researchers benefit from the existing knowledge base $A_{i t}$ to prospect for new designs. The total number of ideas specific to sector $i$, with $i=\{a, n\}$, that the $\mathrm{R} \& \mathrm{D}$ activity delivers by the end of the period is given by

$$
A_{i t+1}=\mu A_{i t}^{\phi} L_{A_{i t}}^{\lambda-1} L_{A_{i t}}
$$

where $L_{A_{i t}}$ is the number of workers employed in $R \& D$ directed to sector $i$.

There are several features of this $R \& D$ specification that are worth emphasizing. First, the LHS is not written in increments, as most of the literature does, but in levels. This is, however, consistent with the idea that technological levels cannot decrease. The reason is that, even though innovations cannot depreciate, they can become obsolete which is what occurs every period in our model. In particular, as in Jones and Williams (2000), we assume that new generations of inventions come in packages. A package is composed of both upgrades of old capital designs and completely new ones. The key is that the whole new vintage or package of ideas $\left(A_{i t+1}\right)$ has to be adopted together, which displaces the old one $\left(A_{i t}\right)$. 
Notice that even though technology comes in "clusters", the final-goods producer's problem described above does not use the package as the decision unit; what the agent does is maximize with respect to each individual idea. In this, we implicitly assume that new technologies are linked in the sense that the adoption of one implies the adoption of the others, but the agent does not recognize the external effect caused by the expansion of different varieties (captured by parameter $A_{i t}$ in equation (20) below). ${ }^{7}$ Alternatively, we could have considered the case where the adopting firm fully recognizes and internalizes the external effect. However, this should not have any significant effect on our results; final-goods producer would internalize the externality that the discovery of new designs brings to his production technology, thus getting closer to the central planner's solution. While demand for intermediates would become stronger, maybe amplifying the productivity and production gap between agriculture and non-agriculture, there will be no substantive change in the results. $^{8}$

Under the above assumptions, expression (11) holds as long as $A_{i t+1} \geq A_{i t}$. In addition, the adoption of the new package, besides bringing technological upgrades, needs to be profitable - notice that producers could continue using old designs purchased in perfectly competitive markets because patents last for one period. The appendix shows that the new vintage will be adopted if and only if the markup $\eta_{i}$ charged by monopolists is below $\left(A_{i t} / A_{i t-1}\right)^{(1-\alpha) / \alpha}$. For the sake of simplicity, we do not impose this condition and as shown later on, this should not have any effect on the main results of the paper. The reason being that the markup and the rate of technical change reinforce each other in the same direction when the condition is binding. As a result, the main consequence of a markup that followed TFP growth would be an amplification of the cross-sector differences in TFP growth.

Second, returns to labor at the individual and aggregate levels differ. On the one hand, investment displays constant returns at the individual level. On the other,

\footnotetext{
${ }^{7}$ Think of computers for example. Our assumption says that if the firm decides to buy the new hardware vintage, it is also forced to buy new versions of each single software that the agent uses because old versions are not compatible with the new hardware. This does not necessarily mean that the agent realizes that there is an external effect from using more intermediates.

${ }^{8}$ We thank a referee for pointing this technically important and substantive alternative to us.
} 
the term $L_{A_{i t}}^{\lambda-1}$ implies that researchers generate negative externalities to each other, which can be a consequence of patent races. The result is that the $R \& D$ technology at the aggregate level shows diminishing returns $(0<\lambda<1)$ to $\mathrm{R} \& \mathrm{D}$ effort. More specifically, in the symmetric equilibrium in which firms end up, expression (11) becomes:

$$
A_{i t+1}=\mu A_{i t}^{\phi} L_{A_{i t}}^{\lambda}
$$

Finally, the $R \& D$ specification allows for intertemporal knowledge spillovers $(0<$ $\phi<1)$.

After coming up with new innovations, inventors obtain patents that are immediately sold. Intermediate-goods producers who purchase these patents invest capital at the end of date $t$ to build producer-durable units that will be available for finalgoods manufacturing at $t+1$ at monopoly prices. The outcome of this entire process is that the firm that sells the intermediate goods obtains an amount of profits equal to $\pi_{i t}$, given by expression (10).

The solution to the R\&D allocation problem is characterized by the next two conditions:

$$
\begin{gathered}
Q_{i t} A_{i t+1}=w_{t} L_{A_{i t}}, \\
Q_{i t}=\frac{\pi_{i t+1}}{1+r_{t+1}}=(\eta-1) x_{i t+1} .
\end{gathered}
$$

Free entry implies that total revenues from the sale of designs at the end of the period must equal the cost of $\mathrm{R} \& \mathrm{D}$. Calling $Q_{i t}$ the price of the patent, we then get the non-arbitrage condition given by expression (13). Intermediate-goods producers will buy the patent and produce under monopolistic competition next period if the price of the patent does not exceed the present value of expected profits. But in equilibrium they must be indifferent between producing and not, so condition (14) must also hold.

\subsection{Market clearing and aggregate outcomes}

The agricultural sector produces output that is used for final consumption, while the non-agricultural sector generates output that can be used for final consumption and 
saved as capital. Hence, market clearing in goods markets requires:

$$
Y_{a t}=L_{t-1} c_{a t}
$$

and

$$
Y_{n t}=L_{t-1} c_{n t}+I_{t}
$$

where $I_{t}$ is gross investment in capital at time $t$.

Let us now focus on input markets. Labor is supplied inelastically by consumers, therefore in equilibrium:

$$
L_{t}=\sum_{i=a, n} L_{i t}+\sum_{i=a, n} L_{A_{i t}} .
$$

Saving in our model economy is entirely due to salary income, and is employed to construct physical capital and finance the purchase of patents:

$$
w_{t} L_{t}=K_{t+1}+\sum_{i=a, n} Q_{i t} A_{i t+1} .
$$

In the last equality, $K_{t}$ represents the aggregate capital stock in the economy at time $t$. Since producer durables fully depreciate upon use, it follows that:

$$
I_{t-1}=\sum_{i=a, n}\left[\int_{0}^{A_{i t}} x_{i t}(z) d z\right]=\sum_{i=a, n} A_{i t} x_{i t}=K_{t} .
$$

In turn, the capital stock in sector $i$ can be written as $K_{i t}=\int_{0}^{A_{i t}} x_{i t}(z) d z=A_{i t} x_{i t}$. Furthermore, given that prices and use of intermediate goods are the same within both sectors, we can rewrite equation (4) at the aggregate level as:

$$
Y_{i t}=\left(A_{i t} L_{i t}\right)^{1-\alpha} K_{i t}^{\alpha}=L_{i t} A_{i t}^{1-\alpha} k_{i t}^{\alpha}
$$

where $k_{i t}$ gives the capital labor ratio $K_{i t} / L_{i t}$ in sector $i$ at date $t$.

This expression, and optimality conditions (6)-(9) imply that:

$$
\begin{aligned}
& 1+r_{t}=\frac{\alpha}{\eta} P_{i t} A_{i t}^{1-\alpha} k_{i t}^{\alpha-1}, \\
& w_{t}=(1-\alpha) P_{i t} A_{i t}^{1-\alpha} k_{i t}^{\alpha} .
\end{aligned}
$$

Then

$$
k_{a t}=k_{n t},
$$


and

$$
P_{a t}=\left(\frac{A_{n t}}{A_{a t}}\right)^{1-\alpha} .
$$

Defining $k_{t}=K_{t} / L_{t}$, it follows from (19) that:

$$
\left(l_{a t}+l_{n t}\right) k_{i t}=k_{t} .
$$

From (13), (14) and (18), we get:

$$
k_{t+1}(1+n)(\eta-1)=w_{t}\left(l_{A_{a t}}+l_{A_{n t}}\right),
$$

In turn, equations (13), (14), (17), (18) and (25) deliver $k_{i t}=\eta k_{t}$. An implication of all the above is that the ratio of the output shares equals the ratio of the labor shares:

$$
\frac{P_{a t} y_{a t} l_{a t}}{y_{n t} l_{n t}}=\frac{l_{a t}}{l_{n t}} .
$$

\subsection{The equation system}

The following equations, along with (21) and (22), provide the system that characterizes dynamics in this economy as a function of prices and predetermined stocks:

$$
\begin{gathered}
\left(\frac{P_{a t}}{\gamma_{a}}\right)^{\varepsilon}\left(c_{a t}-\bar{c}_{a}\right)=\left(\frac{1}{\gamma_{n}}\right)^{\varepsilon}\left(c_{n t}-\bar{c}_{n}\right), \\
A_{i t+1}=\mu A_{i t}^{\phi}\left[l_{A_{i t}} L_{t}\right]^{\lambda}, \\
k_{t+1}(1+n)+w_{t}\left(l_{A_{a t}}+l_{A_{n t}}\right)=w_{t}, \\
P_{a t+1} c_{a t+1}+c_{n t+1}=\left(1+r_{t+1}\right) w_{t}, \\
y_{a t} l_{a t}=\frac{c_{a t}}{1+n}, \\
y_{n t} l_{n t}=\frac{c_{n t}}{1+n}+k_{t+1}(1+n), \\
y_{i t}=A_{i t}^{1-\alpha} k_{t}^{\alpha} l_{i t}, \\
l_{a t}+l_{n t}+l_{A_{a t}}+l_{A_{n t}}=1, \\
\frac{l_{a t+1}}{l_{n t+1}} \frac{l_{A_{n t}}}{l_{A_{a t}}}=1,
\end{gathered}
$$




$$
\frac{k_{n t}}{k_{t}}=\eta
$$

where $l_{i t}$ and $l_{A_{i t}}$ are the fractions of the labor force in the final goods and $R \& D$ of sector $i$ at date $t$, respectively.

The above system simplifies to:

$$
\begin{gathered}
A_{i t+1}=\mu A_{i t}^{\phi}\left[l_{A_{n t}} L_{t}\right]^{\lambda}, \\
P_{a t}=\left(\frac{A_{n t}}{A_{a t}}\right)^{1-\alpha}, \\
\left(c_{n t}-\bar{c}_{n}\right) \sum_{i=a, n} P_{i t}^{1-\varepsilon}\left(\frac{\gamma_{i}}{\gamma_{n}}\right)^{\varepsilon}+\sum_{i=a, n} P_{i t} \bar{c}_{i}=\alpha^{2} A_{n t}^{1-\alpha}\left(\eta k_{t}\right)^{\alpha}(1+n), \\
k_{t+1}=\frac{\alpha(1-\alpha) w_{t}}{(1+n)}, \\
l_{a t}=\frac{P_{a t}^{-\varepsilon}\left(\frac{\gamma_{a}}{\gamma_{n}}\right)^{\varepsilon}\left[\alpha^{2} A_{n t}^{1-\alpha}\left(k_{t} / \alpha\right)^{\alpha}(1+n)-\bar{c}_{n}\right]+\bar{c}_{a}}{\left[1+P_{a t}^{1-\varepsilon}\left(\frac{\gamma_{a}}{\gamma_{n}}\right)^{\varepsilon}\right] A_{a t}^{1-\alpha}\left(k_{t} / \alpha\right)^{\alpha}(1+n)} \\
l_{n t}=\alpha-l_{a t}, \\
l_{A_{a t}}=\left(\frac{1}{\alpha}-1\right) l_{a t+1}, \\
l_{A_{n t}}=(1-\alpha)-l_{A_{a t}}, \\
L_{t} / L_{t-1}=1+n ;
\end{gathered}
$$

with $k_{t}, A_{i t}, L_{t}$ being predetermined.

\section{Dynamics of Structural Change}

The observed change in the contribution of the primary sector to GDP in the last two hundred years has been impressive. The share of agriculture in US national income, for example, went down from roughly $20 \%$ in 1850 to around $0.7 \%$ in year 2000 . At the same time, growth of TFP has been higher in farming than in the rest of the economy in the last 90 years. This pattern of relative TFP growth is supported by evidence suggesting that the relative price of agricultural goods rose over the period 1880 to 1920 and declined after that. ${ }^{9}$

\footnotetext{
${ }^{9}$ See, for example, Caselli and Coleman (2001), Kongsamut et al. (2001), and Johnson (2002).
} 
This section carries out numerical experiments to analyze the transitional dynamics of the model. Our goal is to see whether the unified theory can reproduce these stylized facts and, therefore, encompass the two traditional explanations of the structural transformation. We begin by assigning values to the different parameters, and decide on the starting point of the simulation. For this, we employ the very long-run equilibrium towards which variables converge.

\subsection{Unbalanced growth and the asymptotic steady state}

Our model exhibits unbalanced growth model because of the non-homotheticity of preferences. As Kongsamut et al. (2001) show, in this framework variables only reach a constant growth rate in the particular case where $\bar{c}_{a}\left(P_{a t} / \gamma_{a}\right)^{\varepsilon}=\bar{c}_{n}\left(1 / \gamma_{n}\right)^{\varepsilon}$. In all other scenarios, variables approach and get infinitely close to the balanced-growth path associated with the zero subsistence-consumption case.

When $\bar{c}_{a}=\bar{c}_{m}=0$, per capita variables and wages grow at the same rate along the balanced-growth path, and this rate equals the rate of technological change. The rest of the variables, and in particular, the labor shares, the price of agricultural goods, and the interest rate remain constant.

Specifically, let $G_{z}$ be the gross growth rate of variable $z$, and eliminate the time index to denote steady-state values. Clearing conditions (15)-(19) imply that $G_{Y_{a}}=G_{c_{a}} G_{L}, G_{Y_{n}}=G_{c_{n}} G_{L}=G_{K}$, and $G_{L_{a}}=G_{L_{n}}=G_{L_{A_{a}}}=G_{L_{A n}}=1+n$. Equations (27) and (28) imply that $P_{a t}$ remains constant at steady state because $G_{A_{a}}=G_{A_{n}}=(1+n)^{\lambda /(1-\phi)}$.

Equation (20) then implies that $G_{Y_{i}}=G_{A_{i}}$. Finally, given the output aggregate $Y_{t}=P_{a t} Y_{a t}+Y_{n t}$, we obtain that

$$
G_{y}=(1+n)^{\lambda /(1-\phi)}
$$

where $y$ is per capita income.

Table 1: Benchmark parameter values

\begin{tabular}{cccccccc}
\hline \hline$\lambda$ & 0.50 & $\gamma_{a}$ & 0.00004 & $\bar{c}_{a}$ & 0.05 & $\alpha$ & 0.66 \\
$\phi$ & 0.75 & $n$ & $0.01^{30}$ & $\bar{c}_{m}$ & 0 & $\varepsilon$ & 0.5 \\
\hline \hline
\end{tabular}




\subsection{Calibration}

Table 1 shows the parameter values chosen. An intermediate value is assigned to the degree of diminishing returns to $R \& D$ effort, $\lambda=0.5$. The very long-run gross growth rate of per capita income $G_{y}$ is equalized to 1.8113 , which is the consequence of growing annually at a 2 percent during one period or 30 years. The annual growth rate of the population is assumed to be $1 \%$, thus implying for the same reason that $n=$ 0.3478. By equation (36), all these values require that the intertemporal knowledgespillover parameter $\phi$ equals 0.75 .

We think of capital broadly composed of physical as well as human capital components, and therefore choose the capital share $\alpha=0.66$. The value of the elasticity of substitution between consumption goods is taken from Buera and Kaboski (2009), $\varepsilon=0.5$. The minimum-consumption requirement $\bar{c}_{a}$ is equalized to 0.05 , and $\bar{c}_{n}$ to 0. For the weights of the two types of consumption in the utility function, we use the fact that agricultural GDP as a share of total GDP in 2002 was 0.7 percent, as compiled by the Economic Research Service of the USDA using data from the Bureau of Economic Analysis. This share implies, in turn, by equations (15), (16), (26) and (30) that $\gamma_{a}=0.00004$.

To choose initial values of the state variables, we assume that the economy starts from a steady state in which $c_{a t}=\bar{c}_{a}, c_{m t}=0, n=0, G_{A_{t}}=1$, and the markup that intermediate goods producers are able to charge is very small, namely $\eta=$ $1 / 0.997 .{ }^{10}$ This could be a consequence of a poorly developed patent-enforcement system. Equations (15) and (29) then require that $l_{a 0}=\alpha / \eta$. Then, labor market clearing and expression $(27)$ give that $P_{a 0}=(1 / \alpha-1)^{\lambda(1-\alpha) /(1-\phi)},(30)$ that $k_{0}=$ $P_{a 0} \bar{c}_{a}(1-\alpha) /\left[\alpha(1+n)^{2}\right]$, and equation (15) that $A_{a 0}=\left[\bar{c}_{a} /\left(\alpha \eta^{\alpha-1} k_{t}^{\alpha}\right)\right]^{1 /(1-\alpha)}$. Finally, expression (27) provides $A_{m 0}$ and $\mu L_{0}^{\lambda}$.

\footnotetext{
${ }^{10}$ Our starting point resembles a Malthusian stage characterized by economic stagnation, zero population growth, and relatively low levels of R\&D activity. Although our model is one of modern growth in which R\&D effort propels innovation and growth, some features of the Malthusian economy are used as a sensible way to obtain initial coordinates.
} 


\subsection{Results}

Figure 1 presents the adjustment paths for consumption shares (top panel), output shares (middle panel), and TFP growth (bottom panel) for the parameter values and starting coordinates described above. Because expression (26) implies that relative labor shares exactly equal relative output shares, the labor shares are not shown.

The simulation begins in a stagnant economy with a relatively large share of agriculture in GDP of $66 \%$, and an even larger share of agricultural goods in total consumption of $100 \%$. The shocks that provoke the transition are an exogenous increase in the population growth rate from zero to $1 \%$, and the establishment of a strong patent system that allows firms charging their preferred markup $\eta=1 / \alpha$. This is what allows the growth of TFP.

At impact TFP growth achieves its largest values, and then progressively decreases. Higher population is able to generate more ideas, and output and consumption shares start their transition towards an economy in which non-agriculture is the most important activity. The transition is monotonic and relatively fast. The one of output and consumption is almost finished after 7 generations, while that one of TFP growth is still alive after 10 .

The fact that the weight of the primary sector in total GDP declines and the one of the non-agriculture rises as the economy develops is a consequence of the non-homotheticity of preferences, and reproduces a main pattern of the structural transformation. The evolution of TFP, however, is not consistent with the facts. Non-agriculture TFP growth in the model economy is always the fastest, although agriculture eventually converges to the productivity growth rates of the rest of the economy. The predicted patterns do not depend on the value of $\bar{c}_{a}$ nor on the value of $\varepsilon$. In particular, changes in $\bar{c}_{a}$ are fully neutral, whereas increases in the elasticity of consumption-goods substitution only cause the convergence path to be slightly smoother.

These findings suggest that non-homothetic preferences per se cannot account for the evolution of TFP. An alternative is that factors specific to the production technology contribute to the structural transformation. Next we investigate whether 
differences in the intensity of cross-sector knowledge spillovers can help reconcile our theory with the facts.

\section{Cross-Sector Knowledge Spillovers}

Let us now consider that the agricultural sector benefits from spillovers coming from the rest of the economy, in line with evidence provided, for example, by Johnson and Evenson (1999). These authors argue that R\&D spillovers are significant contributors to agricultural productivity growth and that, in particular, sectors such as chemicals, machinery, plastics, fabricated metals, and electric products contribute to it. The agricultural R\&D technology now takes the form:

$$
A_{a t+1}=\mu A_{a t}^{\phi} A_{n t}^{\beta} L_{A_{a t}}^{\lambda} ;
$$

where $\beta>0$ is the spillover parameter.

It is easy to show that the system of equations that characterize the model dynamics remains the same with the exception of the new $R \& D$ technology that produces ideas specific to the primary sector. In particular, the system is now composed of conditions (27) with $i=n,(28)$ to (35), and (37).

A difference compared to the previous scenario is that the price is no longer approaching a constant value because it decreases with $A_{a t}$. This feature of the model implies that, with spillovers, variables approach a balanced growth path only if $\varepsilon=1$; but for $\varepsilon=0.5$, no such reference exists. This lead us to maintaining the calibrated parameters as in Table 1.

To determine the size of the spillover parameter, we look at Bernard and Jones (1996, Table 1) who estimated TFP growth in the agricultural sector during the period 1970-1987 to be double that of the industrial sector. To reproduce this difference between agriculture and non-agriculture in our model after 10 periods, we assign a value $\beta=0.214$.

The computation of the initial values for the different state variables follows the same logic as above. A steady-state equilibrium with $c_{a t}=\bar{c}_{a}, c_{n t}=0, n=0$, and $\eta=1 / 0.997$ still exists, although showing that needs a bit more algebra. Equations 
(15) and (29) again give $l_{a 0}=\alpha / \eta$. In turn, combining expressions (16), (27), and (30) obtains

$$
k_{0}=\left\{\left[\left(\frac{1-\alpha}{\alpha}\right)^{\frac{\lambda}{1-\phi}}\left(\frac{\bar{c}_{a}}{\alpha}\right)^{\frac{1}{1-\alpha}} \eta\right]^{\frac{1}{1+\beta /(1-\phi)}} \frac{(1-\alpha)^{\frac{1}{1-\alpha}}}{\eta}\right\}^{\frac{1}{1+\frac{\alpha}{1-\alpha} \frac{1}{1+\beta /(1-\phi)}}} .
$$

Knowing $k_{0}$, we can easily recover $A_{n 0}, A_{a 0}$, and $\mu L_{0}^{\lambda}$.

Results for consumption shares, output shares and TFP growth are presented in the top, middle and bottom charts of Figure 2, respectively. Starting again from a relatively large share of agriculture in GDP of $66 \%$, an exogenous increase in the population growth rate from zero to $1 \%$, and in the markup from $1 / 0.997$ to $1 / 0.66$ triggers structural transformation and the transition to positive economic growth. The model shows again the highest TFP growth rates at impact, monotonically decreasing after that point. As technology starts improving, the weight of farming in total GDP declines, while the weight of non-agriculture rises. However unlike in the case without spillovers, TFP growth in agriculture is below that for non-agriculture only temporarily. After a few periods, technological change in farming becomes the fastest. These trends are consistent with the main patterns observed in the data.

Regarding comparative dynamics (not shown but available upon request), the elasticity of substitution has an impact although it is relatively small. As $\varepsilon$ rises, convergence becomes a bit slower, and long-run differences in TFP growth between the two sectors become larger. Subsistence consumption requirements, on the other hand, have a significant effect when spillovers are present. In particular, the transition becomes faster as $\bar{c}_{a}$ rises, and differences in TFP growth between the activities get larger. This is due to the initially higher technological level needed in agriculture to feed the population.

\section{Conclusion}

Stephen Turnovsky's work on multi-sector growth models has inspired a vibrant literature that is growing strong to this day. This paper extends this line of research by using dynamic general equilibrium and computational methods, in an attempt to 
develop a theory that unifies two of the traditional explanations of structural change: sector-biased technical change, and non-homothetic preferences. More specifically, we build a multisector overlapping-generations growth model that incorporates both endogenous technical-change and non-homothetic preferences. Following a minimalist approach, the model is based on an expanding-variety setup with only two types of R\&D technologies; one for agriculture, and the other for non-agriculture.

We first ask whether homothetic preferences can be the cause of the observed evolution of sectoral TFP that represents the basic element of the sector-biased technical change hypothesis. The analysis shows that this is not possible. Our baseline model, in which cross-sector differences come from only consumer preferences, predicts that agriculture is the most stagnant activity, a prediction not consistent with evidence.

We then ask a follow-up question: What kind of differences between sectors can be responsible for TFP growth? When we consider knowledge spillovers from the rest of the economy into agricultural $\mathrm{R} \& \mathrm{D}$, the model is able to reproduce evolution of consumption shares, output shares, and TFP growth in agriculture and in nonagriculture consistent with evidence. We therefore conclude that production-side specific factors, such as asymmetries in cross-sector knowledge spillovers, are needed to reconcile the model with the main patterns observed in the data.

Although directed technical change can reconcile the two traditional theories of structural transformation, our findings depart from the sector-biased technical change hypothesis in one crucial way. The evolution of TFP does not need to be linked to a relatively low elasticity of consumption-goods substitution to be consistent with structural transformation. Endogenous technical change allows the agricultural sector to shift from being the most stagnant to being the most vibrant sector, therefore freeing labor to the rest of the economy, irrespective of the value of the elasticity of substitution.

It is also interesting to note that our finding highlighting the need for cross-sector variability and knowledge spillover effects is the main research topic in a related literature that tries to explain cross-country growth variation by examining sectoral resource (mis)allocations and their effects on aggregate TFP (see e.g. Restuccia and 
Rogerson, 2008, and Hsieh and Klenow, 2009).

We conclude with a cautionary remark. Our analysis provides the simplest possible disaggregated setup to consider a unified theory of structural transformation. More complicated multisector models are likely to be more successful in matching the data. For example, future work could consider even more disaggregated setups, and search for sectoral asymmetries in manufacturing and services. In addition, recent emphasis on producing more and better quality data at the sectoral level should provide further incentives to extend the analysis in this paper. 


\section{A Restricted markup}

All available designs become displaced by updates after one period. A final good producer at $t$ can purchase the varieties $A_{i t-1}$ at the marginal cost price or buy the new cluster $A_{i t}$ of intermediate goods at markup price. The profits of a producer of final goods in each case are, respectively,

$$
\begin{gathered}
\Pi_{i t}^{\text {old }}=x_{i t}^{\text {old }}\left[\left(1+r_{t}\right) A_{i t-1}\left(\frac{1}{\alpha}-1\right)-w_{t}\left(\frac{\left(1+r_{t}\right)}{\alpha P_{i t}}\right)^{\frac{1}{1-\alpha}}\right], \\
\Pi_{i t}^{\text {new }}=x_{i t}^{\text {new }}\left[\eta_{i}\left(1+r_{t}\right) A_{i t}\left(\frac{1}{\alpha}-1\right)-w_{t}\left(\frac{\eta_{i t}\left(1+r_{t}\right)}{\alpha P_{i t}}\right)^{\frac{1}{1-\alpha}}\right] .
\end{gathered}
$$

It follows that the final good producer will adopt the new technology if and only if

$$
\eta_{i} \leq\left(\frac{A_{i t}}{A_{i t-1}}\right)^{\frac{1-\alpha}{\alpha}}
$$




\section{References}

[1] Acemoglu, D. (2002), "Directed Technical Change," Review of Economic Studies $69,781-810$.

[2] Acemoglu, D. (2003), "Labor- and Capital-Augmenting Technical Change," Journal of European Economic Association 1, 1-37.

[3] Acemoglu, D. (2009), Introduction to Modern Economic Growth, Chapter 20, Princeton University Press.

[4] Alvarez-Cuadrado, F., G. Monteiro and S. Turnovsky. (2004), "Habit Formation, Catching up with the Joneses, and Economic Growth," Journal of Economic Growth 9, 47-80.

[5] Baumol, W. (1967). "Macroeconomics of Unbalanced Growth: The Anatomy of Urban Crisis," American Economic Review 57, 415-426.

[6] Bernard B. and C.I. Jones. (1996), "Productivity Across Industries and Countries: Time Series Theory and Evidence," Review of Economics and Statistics $78,135-146$.

[7] Buera, J.F. and J.P. Kaboski. (2009), "Can Traditional Theories of Structural Change Fit the Data?" Journal of the European Economic Association 7, 469477 .

[8] Caballero, R.J. and A.B. Jaffe. (1993), "How High are the Giants' Shoulders?," in Olivier Blanchard and Stanley Fischer, eds., NBER Macroeconomics Annual, Cambridge, MA: MIT Press, 15-74.

[9] Caselli, F., and W.J. Coleman. (2001), "The U.S. Structural Transformation and Regional Convergence: A Reinterpretation" Journal of Political Economy 109, 584-616.

[10] Chenery, H. (1960), "Patterns of Industrial Growth," American Economic Review 50, 624-654.

[11] Chenery H. and T.N. Srinivasan. (1988), Handbook of Development Economics, Volume 1, Amsterdam: North Holland.

[12] Clark, C. (1940), The Conditions of Economic Progress (MacMillan: London).

[13] Echevarria, C. (1997), "Changes in Sectoral Composition Associated with Economic Growth," International Economic Review 38, 431-452.

[14] Eicher, T. and S. Turnovsky. (1999a), "A Generalized Model of Economic Growth," Economic Journal 109, 394-415. 
[15] Eicher, T. and S. Turnovsky. (1999b), "Convergence in a Two-Sector Non-Scale Growth Model," Journal of Economic Growth 4, 413-429.

[16] Eicher, T. and S. Turnovsky. (2001), "Transition Dynamics in Non-Scale Models," Journal of Economic Dynamics and Control 25, 85-113.

[17] Fisher, W.H. and S. Turnovsky. (1998), "Public Investment, Congestion, and Private Capital Accumulation," Economic Journal 108, 399-413.

[18] Iscan, T. (2010), "How Much Can Engel's Law and Baumol's Disease Explain the Rise of the Service Employment in the United States?" The B.E. Journal of Macroeconomics 10, issue 1 (Contributions), article 26.

[19] Johnson, D.K.N. (2002), "Comment on 'The U.S. Structural Transformation and Regional Convergence: A Reinterpretation'," Journal of Political Economy 110, 1414-1418.

[20] Johnson, D.K.N., and R.E. Evenson. (1999), "R\&D Spillovers to Agriculture: Measurement and Application," Contemporary Economic Policy 17, 432-456

[21] Jones, C.I. (1995), "R\&D-Based Models of Economic Growth," Journal of Political Economy, 103:759-784.

[22] Jones, C.I, and J.C. Williams. (2000), "Too much of a good thing? The economics of investment in R\&D," Journal of Economic Growth, 65-85.

[23] Kongsamut, P., S. Rebelo and D. Xie. (2001), "Beyond Balanced Growth," Review of Economic Studies 68, 869-882.

[24] Kuznets, S. (1957), "Quantitative Aspects of the Economic Growth of Nations; II," Economic Development and Cultural Change 4, 3-11L.

[25] Kuznets, S. (1966). Modern Economic Growth: Rate, Structure, and Spread. New Haven, Conn.: Yale University Press.

[26] Ngai, L.R., and C.A. Pissarides. (2007), "Structural Change in a Multi-Sector Model of Growth," American Economic Review 97, 429-443.

[27] Papageorgiou, C. and F. Perez-Sebastian. (2004), "Can Transition Dynamics Explain the International Output Data?" Macroeconomic Dynamics 8, 466-492.

[28] Papageorgiou, C. and F. Perez-Sebastian. (2006), "Dynamics in a Non-Scale R\&D Growth Model with Human Capital: Explaining the Japanese and South Korean Development Experiences," Journal of Economic Dynamics and Control 30, 901-930.

[29] Papageorgiou, C. and F. Perez-Sebastian. (2007), "Is the Asymptotic Speed of Convergence a Good Proxy for the Transitional Growth Path?" Journal of Money Credit and Banking 39, 1-24. 
[30] Parente, S., R. Rogerson, and R. Wright. (2000), "Homework In Development Economics: Household Production and the Wealth of Nations," Journal of Political Economy 108, 680-688.

[31] Romer, P. (1990), "Endogenous Technological Change," Journal of Political Economy, 98:S71-103.

[32] Strulik, H., and J. Weisdorf. (2008), "Population, food, and knowledge: a simple unified growth theory," Journal of Economic Growth 13(3), 195-216, September.

[33] Turnovsky, S. (2004), "The Transitional Dynamics of Fiscal Policy: Long-run Capital Accumulation and Growth," Journal of Money, Credit, and Banking 36, 883-910. 
Figure 1: Dynamic paths for consumption shares (top), output shares (middle) and TFP growth (bottom)
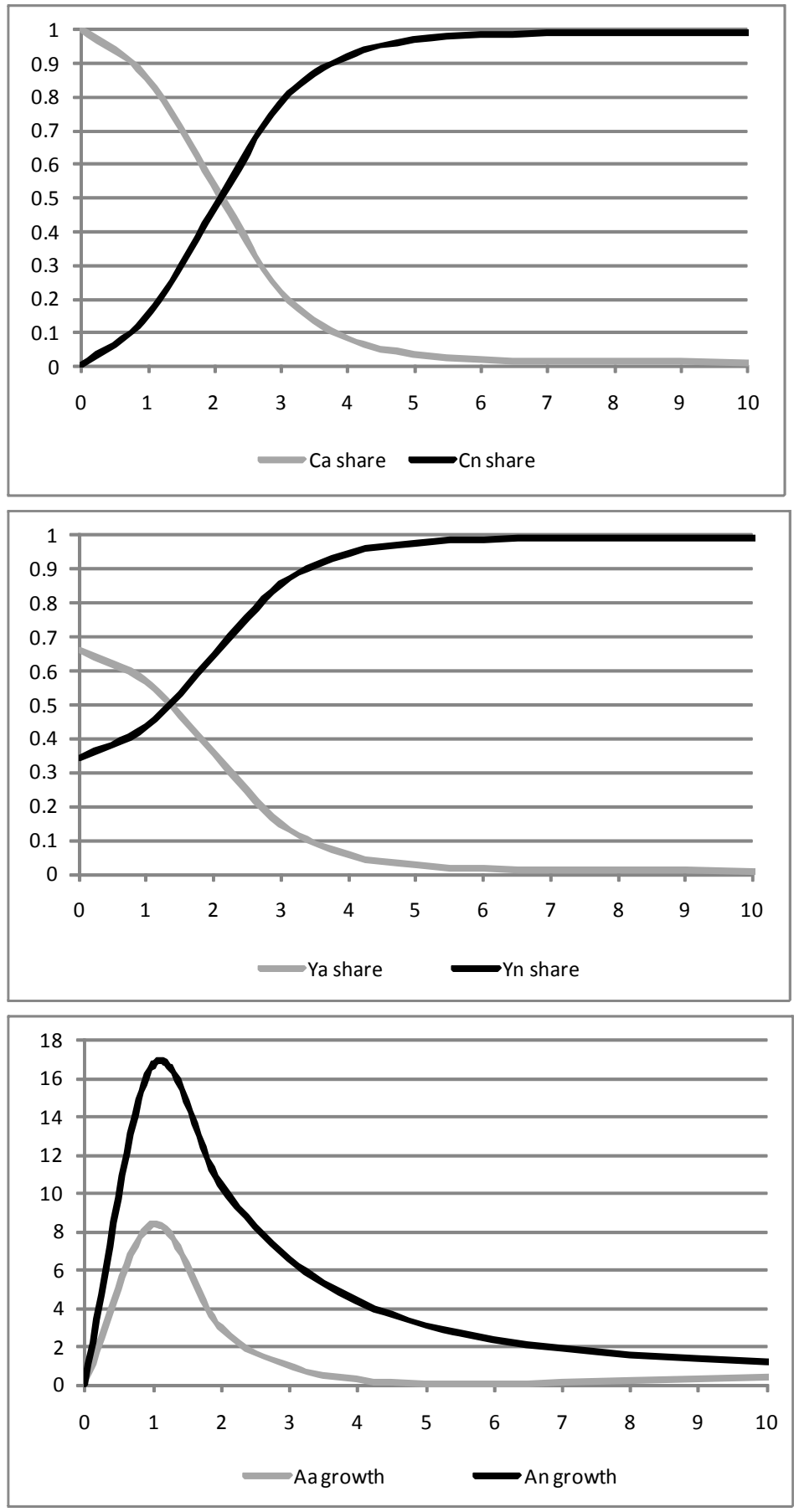
Figure 2: Dynamic paths for consumption shares (top), output shares (middle) and TFP growth (bottom), case with spillovers
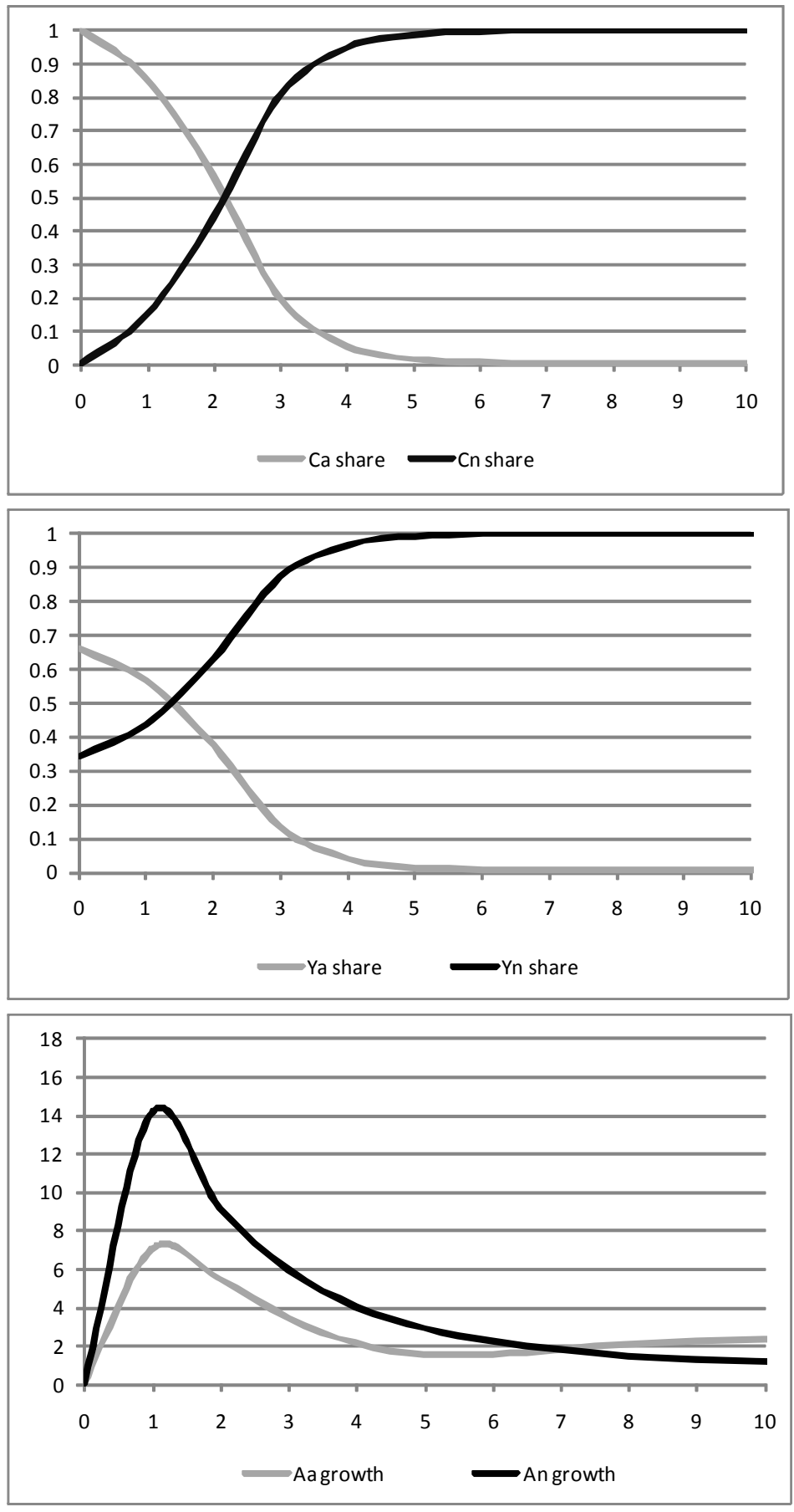